\title{
Quantitative comparison of impeller-flowmeter and particle-size-distribution techniques for the characterization of hydraulic conductivity variability
}

\author{
Marco Barahona-Palomo • Monica Riva • \\ Xavier Sanchez-Vila • Enric Vazquez-Sune • \\ Alberto Guadagnini
}

be associated with different (albeit comparable) measurement (support) scales. It also matches published results on interpretations of variability of geostatistical descriptors of hydraulic parameters on multiple observation scales. The analysis strengthens the idea that hydraulic conductivity values and associated key geostatistical descriptors inferred from different methodologies and at similar observation scales (of the order of tens of $\mathrm{cm}$ ) are not readily comparable and should not be embedded blindly into a flow (and eventually transport) prediction model.

Keywords Hydraulic properties · Geostatistics · Grainsize analysis · Borehole flowmeter · Hydraulic conductivity

\section{Introduction}

Received: 4 January 2010 / Accepted: 28 January 2011

Published online: 19 February 2011

(C) Springer-Verlag 2011

Electronic supplementary material The online version of this article (doi:10.1007/s10040-011-0706-5) contains supplementary material, which is available to authorized users.

M. Barahona-Palomo $\cdot$ E. Vazquez-Sune

Hydrogeology Group, Department of Geosciences, Institute of Environmental Assessment and Water Research (IDAEA-CSIC), Jordi Girona 18, 08034 Barcelona, Spain

\section{Riva $\cdot$ A. Guadagnini}

Dipartimento di Ingegneria Idraulica, Ambientale, Infrastrutture Viarie, Rilevamento (DIIAR),

Politecnico di Milano, Piazza L. Da Vinci 32, 20133 Milano, Italy

M. Barahona-Palomo $(\bullet) \cdot X$. Sanchez-Vila

Hydrogeology Group,

Dept. of Geotechnical Engineering and Geosciences,

Universitat Politecnica de Catalunya-Barcelona TECH,

Jordi Girona 31, 08034 Barcelona, Spain

e-mail: marco.barahona@upc.edu
Proper modeling of groundwater flow and subsurface transport requires assimilation of data on hydraulic parameters which are representative of scales that are relevant for the problem analyzed. Commonly used measurement and interpretation techniques are based on pumping tests. These typically provide equivalent or interpreted hydraulic parameters that are somehow integrated values within a given volume around the pumping and observation wells (e.g., Sanchez-Vila et al. 2006). While most of these interpreted values can be used to estimate the average flow behavior at some large scale, they can be of limited use for local-scale models, when a detailed characterization of spatial variability is needed. In particular, intermediate-scale models (i.e., models involving horizontal length scales of the order of a few hundreds of meters) need a detailed knowledge of the architecture of the groundwater system together with the description of the smallscale variability of parameters such as hydraulic conductivity, $K$, at scales ranging from the order of $10^{-1}-10^{0} \mathrm{~m}$. 
In this context, Riva et al. $(2008,2010)$ showed that a detailed geostatistical characterization based on sedimentological data collected at the centimeter scale was essential to provide a proper stochastically based interpretation of the salient features of depth-averaged and multilevel breakthrough curves measured within an alluvial aquifer during a forced-gradient tracer test performed on a scale of about $50 \mathrm{~m}$.

Historically, a number of methods have been proposed to obtain estimates of hydraulic parameters at scales of a few centimeters/decimeters. These methods can be typically divided into two categories: (1) field-, and (2) laboratory-based methods. The latter can be based on the analysis and interpretation of observations taken on undisturbed or disturbed samples. Each particular method may provide a different parameter estimate that can then be associated with the same location within the natural aquifer. Therefore, it is relevant to properly compare the characterization of the system ensuing from estimates of hydraulic parameters obtained with different interpretive methods but representative of support scales of the same order of magnitude.

Amongst the available techniques, the frequently used methods based on the analysis of (1) grain-size distribution (GSD) and (2) impeller flowmeter (IFM) information are particularly relevant. Particle-size distribution methods

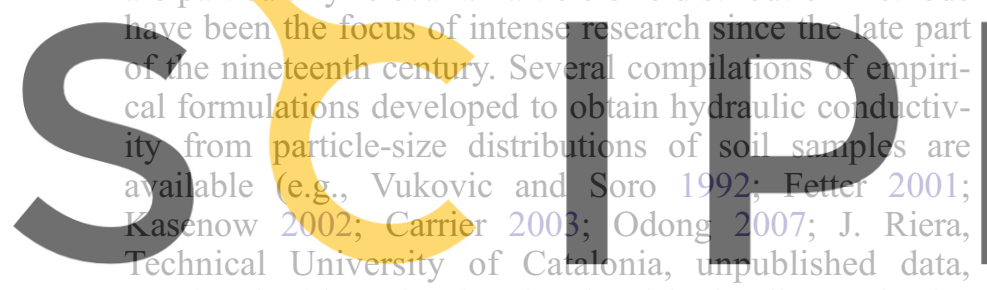
2010). The idea of estimating local hydraulic conductiv-

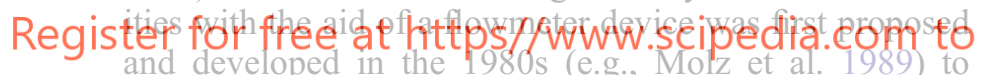
estimate hydraulic parameters in intermediate to high permeability formations. Some analyses have presented the main features of the GSD and IFM methodologies to obtain estimates of $K$ at the small scale (e.g. Molz et al. 1989; Wolf et al. 1991; Hess et al. 1992; Stauffer and Manoranjan 1994; Boman et al. 1997; Carrier 2003; Odong 2007). Qualitative comparisons between estimated conductivity values and associated key geostatistical parameters based on both methods can be found in the literature (e. g., Wolf et al. 1991; Stauffer and Manoranjan 1994; Boman et al. 1997).

This work focuses on the impact that estimates of $K$ obtained by means of (1) empirical formulations based on particle-size distributions and (2) in-situ hydraulic testing performed by borehole impeller flowmeters can have on the geostatistical characterization of spatial variability of hydraulic conductivity. It is emphasized that, while the measurement scale associated with particle-size-based methods is sufficiently clear, the precise definition of the support scale of flowmeter-based hydraulic conductivities is still lacking (e.g., Beckie 1996; Zlotnik et al. 2000; Zlotnik and Zurbuchen 2003a). Here, for the purpose of discussion, it is assumed that the characteristic length scales of flowmeter measurements and GSD estimates, albeit different, are of the same order of magnitude as the borehole diameter, i.e. $\left(10^{-1} \mathrm{~m}\right)$. It is with this spirit that the analyses and comparisons on a dataset collected in the alluvial unconfined aquifer of Tübingen, Germany, are performed. This dataset was partly used by Neuman et al. $(2007,2008)$ for the probabilistic interpretation of crosshole pumping tests and for a multiscale geostatistical characterization of the aquifer. In the same experimental site, Riva et al. (2006, 2010) performed Monte Carlobased analyses of a tracer test. As detailed in section The Tübingen site dataset, GSD- and IFM-based $K$ estimates are here available at a set of coinciding locations in the system. The analysis of the main statistics and key geostatistical parameters characterizing the heterogeneity of hydraulic conductivities estimated with GSD and IFM methods at the site is presented. The degree of correlation between $K$ values obtained with the different methodologies examined is then explored. The results provide evidence of the lack of correlation between GSD- and IFM-based hydraulic conductivity values.

Comparisons similar to the one presented in this work were performed at the Savannah River Site, South Carolina, USA (Boman et al. 1997) and at the Cape Cod Site, USA (Hess et al. 1992). In the former site, both IFM- and GSD-based $K$ measurements/estimates

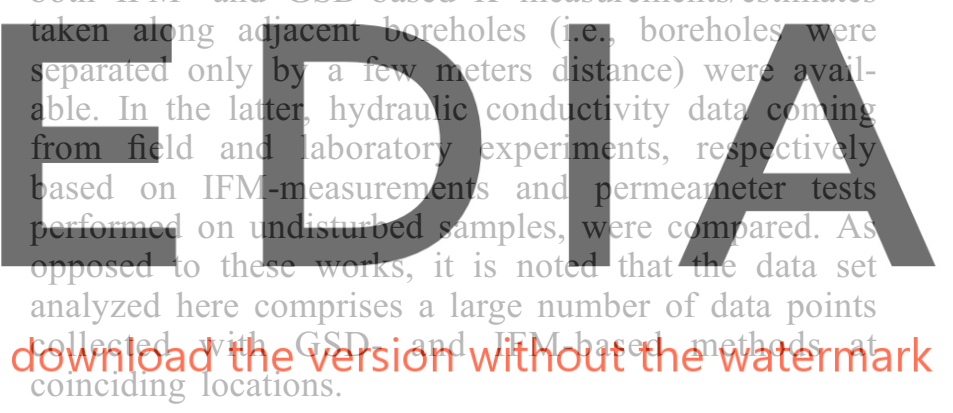

\section{Methodology}

For completeness and ease of reference, the salient features of the IFM and GSD methodologies used to estimate small-scale hydraulic conductivity values are briefly reviewed.

\section{Estimates of hydraulic conductivity from impeller flowmeter (IFM) data}

The borehole flowmeter methodology was developed and presented by Hufschmied (1986), Rehfeldt et al. (1989) and Molz et al. (1989). The technique relies on pumping at a fixed rate from a screened well to attain (approximately) horizontal flow in the surrounding of the well and vertical flow within the well bore. The distribution of horizontal hydraulic conductivity along the borehole is then based on measured values of the vertical distribution of discharge within the pumping well. The latter are taken by means of a down-hole impeller flowmeter. The flowmeter probe is initially positioned at the bottom of 
the screened interval while pumping. It is then systematically moved upwards and is maintained at a given depth until a stable velocity recording is obtained. The vertical distribution of hydraulic conductivity is then obtained according to (Molz et al. 1989 and 1994)

$\frac{K_{F M, i}}{\bar{K}}=\frac{\Delta Q_{i} / Q_{P}}{\Delta b_{i} / B}$

Here, $\bar{K}$ is the average hydraulic conductivity estimated at the site, e.g., from a pumping test; $Q_{\mathrm{P}}$ is the total pumping rate from the well; $B$ is the screened thickness of the aquifer; $\Delta Q_{\mathrm{i}}$ is the discharge measured within the $\mathrm{i}$-th sampling interval of vertical thickness $\Delta b_{\mathrm{i}}$; and $K_{\mathrm{FM}, \mathrm{i}}$ is the estimated value for the hydraulic conductivity representative of the sampled $i$-th vertical interval. Perfect layering of the aquifer system in the proximity of the well is a key assumption at the basis of $\mathrm{Eq}$. (1). Critical points in the interpretation of field information also include well losses (Rehfeldt et al. 1989; Molz et al. 1989). With reference to electromagnetic borehole flowmeters and following, an observation by Boman et al. (1997), Zlotnik and Zurbuchen (2003b) showed that neglecting head losses can lead to biased interpretations. Young (1998) showed that positive skin effects can influence the data analysis based on Eq. (1) at wells without gravel packs located at Columbus Air Force Base, Mississippi
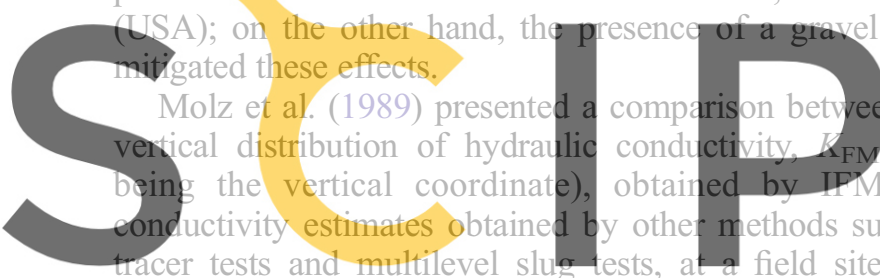

Mobile, Alabama (USA). They concluded that althoug

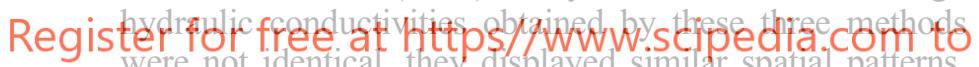

The authors point out that the assumption of a layered.

stratified aquifer in the proximity of the pumping well limits the proper characterization of the unknown three-dimensional distribution of $K$. Several additional studies have been published on intercomparisons between hydraulic conductivity estimates based on the IFM technique and other methods, including dipole flow tests, multilevel slug tests, and permeameter tests (Wolf et al. 1991; Hess et al. 1992; Zlotnik and Zurbuchen 2003a; Butler 2005). With specific reference to comparisons between IFM- and GSD-based conductivity estimates, Whittaker and Teutsch (1999) perform numerical analyses on a hypothetical aquifer and study the impact that simulated flowmeter information and sieve analyses of cores have on the travel times of tracer particles. The authors observed that, whilst the Gaussian simulations based on sieve analyses were better able to represent high permeability lenses and therefore better reproduced the variability of the exhaustive data set, this did not lead to a better prediction of the arrival times of particles. On the contrary, simulations based on data extracted from flowmeter measurements were consistently more accurate, despite their failure to generate regions of high permeability.

\section{Estimates of hydraulic conductivity from grain-size distributions (GSD)}

It is well accepted that hydraulic conductivity is related to the particle-size distribution of granular porous media. An estimate of the hydraulic conductivity of a sample can then be obtained by using information on particle-size distributions in empirical relationships (compilations of several existing relationships can be found, e.g., in Vukovic and Soro 1992; Odong 2007; Cheng and Chen 2007; Payne et al. 2008, and references therein). Grainsize-based methods are typically applied to porousmedium samples and the estimates are assumed to be independent on flow configuration. These methods are appealing for the estimation of hydraulic conductivity because sieve analysis practices are well-established procedures in groundwater investigations and can be performed with moderate experimental effort. Hydraulic conductivity estimates based on GSD information, $K_{G S}$. provided by a series of empirical methods can be synthesized by the following relationship

\section{$K_{G S}=\frac{g}{v} C f(\phi) d_{e}^{2}$}

where $g$ is gravity acceleration, $v$ is the kinematic viscosity of the fluid, $f(\phi)$ is a function of porosity, $\phi, d_{\mathrm{e}}$

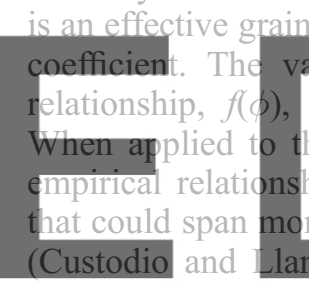

Technical University of Catalonia, unpublished data, 2010). A widely used formulation is that of Kozenycombloalde version without the watermark

$C=8.3 \times 10^{-3} ; \quad f(\phi)=\left[\frac{\phi^{3}}{(1-\phi)^{2}}\right] ; \quad a_{e}=d_{10}$

Here, $d_{10}$ is the grain diameter (in $\mathrm{mm}$ ) that corresponds to $10 \%$ (by weight) of the soil sample passing, and $K_{\mathrm{GS}}$ is given in m/day. Using Eq. (2) requires that porosity measurements be available. In case $\phi$, measurements are not directly available, an estimate of $\phi$ could be obtained by means of the following empirical formula (e.g., Vukovic and Soro 1992)

$\phi=0.255\left(1+0.83^{U}\right) ; \quad U=\left(\frac{d_{60}}{d_{10}}\right)$

where $d_{60}$ is the grain diameter that corresponds to $60 \%$ (by weight) of the sample passing, and $U$ is the coefficient of uniformity. It is noted that, as a result of sample homogenization which might occur during particle-size analysis, values based on GSD methods can be considered as lying in between the two components along the principal directions of the local conductivity tensor (vertical and horizontal if layers are not tilted). 
Table $1 x$ and $y$ in Gau $\beta$-Krüger coordinates, of the boreholes at the Tübingen site. Main characteristics of the flowmeter data: $L$ (length of the vertical interval investigated); $\Delta z_{\min }, \Delta z_{\max }$ (minimum and maximum distance between packers); $d_{1}, d_{2}$ (distances between the ground level and the first and last packer); $Z_{\max }, Z_{\min }$ (vertical elevations of the highest and lowest packers). Number of data available: $N_{I F M}$ (IFM measurements); $N_{G S D}$ (GSD measurements); $N_{M A T C H}$ (number of IFM and GSD data taken at the same vertical elevation within a borehole)

\begin{tabular}{|c|c|c|c|c|c|c|c|c|c|c|c|c|}
\hline Borehole & $\mathrm{x}$ & $\mathrm{y}$ & $\begin{array}{l}\mathrm{L} \\
(\mathrm{m})\end{array}$ & $\begin{array}{l}\Delta Z_{\text {min }} \\
(\mathrm{m})\end{array}$ & $\begin{array}{l}\Delta Z_{\max } \\
\text { (m) }\end{array}$ & $\begin{array}{l}d_{1} \\
(\mathrm{~m})\end{array}$ & $\begin{array}{l}d_{2} \\
(\mathrm{~m})\end{array}$ & $\begin{array}{l}Z_{\max } \\
\text { (m a.s.1) }\end{array}$ & $\begin{array}{l}Z_{\min } \\
\text { (m a.s.l) }\end{array}$ & $N_{\mathrm{IFM}}$ & $N_{\mathrm{GSD}}$ & $N_{\text {MATCH }}$ \\
\hline F0 & $3,508,686$ & $5,377,739$ & 1.40 & 0.05 & 0.15 & 5.06 & 6.46 & 304.52 & 303.02 & 15 & 12 & 4 \\
\hline $\mathrm{F} 1$ & $3,508,629$ & $5,377,746$ & 2.19 & 0.05 & 0.20 & 4.74 & 6.73 & 305.90 & 303.71 & 13 & 10 & 2 \\
\hline $\mathrm{F} 2$ & $3,508,680$ & $5,377,687$ & 2.34 & 0.05 & 0.15 & 4.40 & 6.67 & 305.99 & 303.65 & 23 & 20 & 6 \\
\hline F3 & $3,508,586$ & $5,377,660$ & 0.69 & 0.05 & 0.10 & 8.72 & 9.30 & 301.83 & 301.34 & 9 & 12 & 0 \\
\hline F4 & $3,508,419$ & $5,377,670$ & 1.47 & 0.05 & 0.15 & 4.48 & 5.86 & 306.70 & 305.23 & 15 & 9 & 0 \\
\hline F5 & $3,508,459$ & $5,377,622$ & 2.45 & 0.05 & 0.15 & 4.25 & 6.60 & 306.60 & 304.25 & 23 & 14 & 8 \\
\hline F6 & $3,508,500$ & $5,377,574$ & 0.60 & 0.05 & 0.10 & 3.90 & 4.40 & 306.71 & 306.16 & 7 & 18 & 0 \\
\hline B1 & $3,508,702$ & $5,377,754$ & 0.80 & 0.05 & 0.25 & 4.17 & 4.92 & 305.08 & 304.32 & 8 & 59 & 7 \\
\hline B2 & $3,508,703$ & $5,377,759$ & 1.85 & 0.03 & 0.06 & 3.98 & 5.78 & 305.35 & 303.55 & 32 & 55 & 15 \\
\hline B3 & $3,508,712$ & $5,377,757$ & 3.06 & 0.04 & 0.40 & 3.42 & 6.43 & 305.48 & 302.47 & 41 & 67 & 20 \\
\hline B4 & $3,508,691$ & $5,377,769$ & 4.85 & 0.05 & 0.35 & 3.55 & 8.32 & 305.86 & 301.08 & 65 & 69 & 36 \\
\hline \multirow[t]{2}{*}{ B5 } & $3,508,703$ & $5,377,779$ & 3.45 & 0.05 & 0.30 & 3.38 & 6.78 & 305.82 & 302.42 & 61 & 62 & 14 \\
\hline & & & & & & & & & Total & 312 & 407 & 112 \\
\hline
\end{tabular}

The Kozeny-Carman equation has been applied to a large variety of fine and coarse-grain sediments, ranging from non-plastic, cohesionless silts to sand and gravel mixtures (Carrier 2003; Gallardo and Marui 2007; Odong 2007; Wilson et al. 2008). The method is less reliable for very-poorly sorted soils, or soils with highly irregular shapes (Carrier 2003), as well as for plastic soils (with
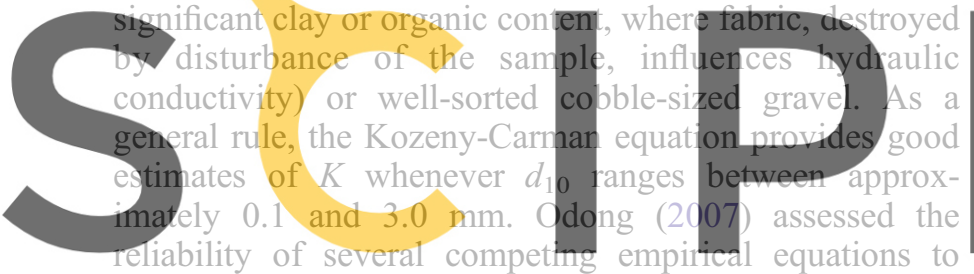

estimate hydraulic conductivity from grain-size distribu-

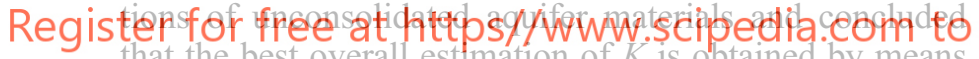
of the Kozeny-Carman formula. Carrier (2003) and Barr (2005) have performed similar comparisons supporting the same conclusion. Examples of acceptable correlation between GSD $K$ estimates and hydraulic tests have been documented by Zlotnik and McGuire (1998) and Cardenas and Zlotnik (2003).

\section{The Tübingen site dataset}

The Tübingen aquifer consists of alluvial material overlain by stiff silty clay and underlain by hard silty clay. The lithostratigraphic characterization has been performed on the basis of the stratigraphy obtained from $150 \mathrm{~mm}$ diameter monitoring wells (Sack-Kühner 1996; Martac and Ptak 2003) and from one $400 \mathrm{~mm}$-diameter pumping well. All wells were drilled to the marly bedrock constituting the impermeable aquifer bottom of variable depth and are surrounded by a gravel pack. The aquifer saturated thickness is about $5 \mathrm{~m}$. Extensive field and laboratory-scale aquifer-investigation procedures were performed at the site, including grain sieve analyses, down-hole impeller flowmeter measurements and pumping tests. The sieve analyses were performed on drill core samples ranging in length from 5 to $26.5 \mathrm{~cm}$ and indicated very heterogeneous, highly conducive alluvial deposits. More than 400 grain distribution curves are available within the test area, distributed along 12 vertical boreholes, providing sufficient information to estimate

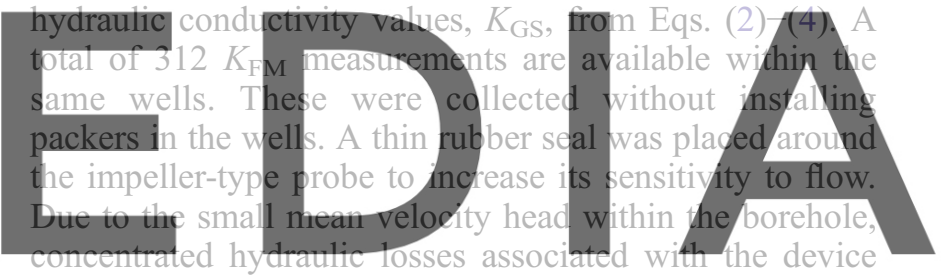

were not considered in the data interpretation. Measure-

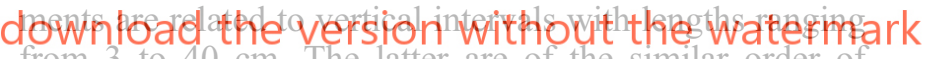
from 3 to $40 \mathrm{~cm}$. The latter are of the similar order of magnitude of a typical length scale of the support (measurement) scale associated with samples on which the GSD-based interpretations are obtained. Table 1 reports the spatial coordinates of the locations of the

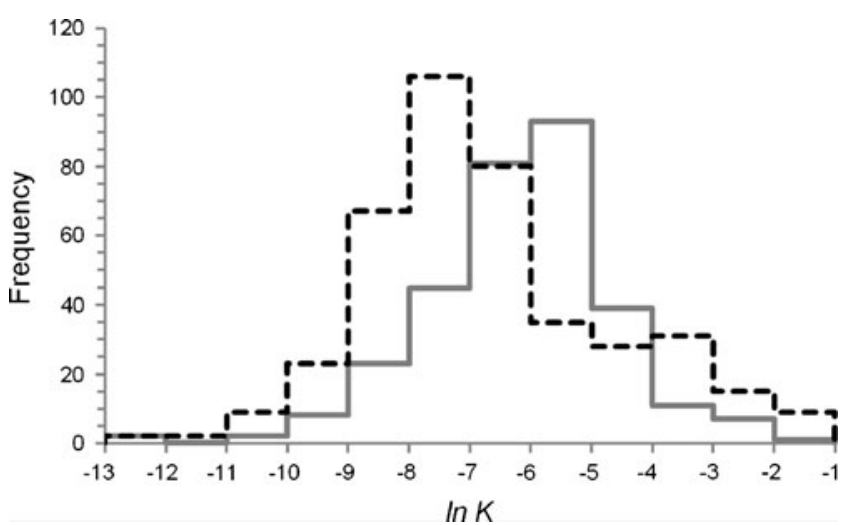

Fig. 1 Histograms of frequency distribution for $\ln K_{F M}$ (continuous gray line) and $\ln K_{G S}$ (discontinuous black line) values when all available points are used. Number of available data points is 312 for $K_{F M}$ and 407 for $K_{G S}$ 
Table 2 Basic univariate statistics for the complete Tübingen site data-sets and for the subsets of conductivity values estimated only at the $N_{M A T C H}=112$ points where GSD and IFM data are jointly available

\begin{tabular}{|c|c|c|c|c|}
\hline & $\begin{array}{l}\text { IFM } \\
N_{\text {IFM }}\end{array}$ & $\begin{array}{l}\text { IFM } \\
N_{\text {MATCH }}\end{array}$ & $\begin{array}{l}\text { GSD } \\
N_{\mathrm{GSD}}\end{array}$ & $\begin{array}{l}\text { GSD } \\
N_{\text {MATCH }}\end{array}$ \\
\hline Minimum $\ln K$ & -12 & -10 & -13 & -9.3 \\
\hline Maximum $\ln K$ & -1.7 & -3.6 & -1.1 & -1.5 \\
\hline Mean $\ln K$ & -6.2 & -6.1 & -6.7 & -6.2 \\
\hline Median $\ln K$ & -6.1 & -5.9 & -7.1 & -6.6 \\
\hline Standard deviation of $\ln K$ & 1.5 & 1.3 & 2.0 & 1.8 \\
\hline Skewness of $\ln K$ distribution & -0.33 & -0.69 & 0.52 & 0.73 \\
\hline Mean $K\left(\times 10^{-3} \mathrm{~m} / \mathrm{s}\right)$ & 6.8 & 4.4 & 12 & 12 \\
\hline Geometric mean of $K\left(\times 10^{-3} \mathrm{~m} / \mathrm{s}\right)$ & 2.1 & 2.3 & 1.2 & 2.0 \\
\hline
\end{tabular}

boreholes where measurements have been performed, together with the main characteristics of the flowmeter data. The table also includes the number of flowmeter and grain-size distribution data, $N_{\mathrm{IFM}}$ and $N_{\mathrm{GSD}}$ respectively. It is noted that it is possible to obtain both GSD and IFM conductivity information at $N_{\mathrm{MATCH}}=112$ coinciding locations in the system. In this work, 'coinciding locations' means a match that considers (1) the length and absolute location of a sample from which GSD has been analyzed, and (2) the location along the vertical of the impeller flowmeter. If the GSD location falls within the interval determined in (2), then the two locations are considered coinciding. This constitutes a rather unique

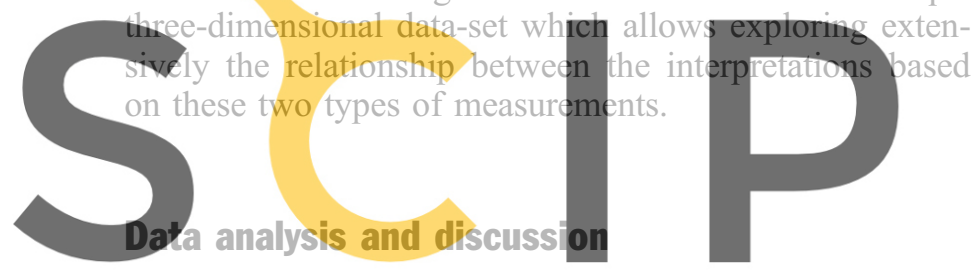

The three-dimensional distributions of hydraulic conduc-

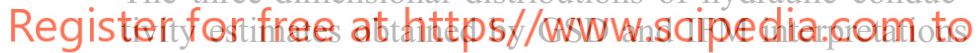
at the site are here presented and discussed in terms of basic univariate statistics and a detailed geostatistical analysis of the available data is performed. The degree of correlation between the different types of measurements at the site is then assessed.

\section{Univariate statistics and geostatistical analysis of the data-set}

Riva et al. (2006) present a geostatistical analysis of the hydraulic conductivity values calculated from grain sieve curves by means of Beyer's model (Beyer 1964). On the basis of section Estimates of hydraulic conductivity from grain-size distributions (GSD), these are interpreted by using Eqs. (2)-(4). A high correlation (not shown) was found between the conductivity values obtained with these two empirical models. For completeness, the key statistics of the measured distributions of $d_{10}$ and $d_{60}$ are reported as electronic supplementary material (ESM).

Uncertainty $u_{\mathrm{K}}$ associated with conductivity values estimated on the basis of Eqs. (2)-(4) and related due to uncertainties in measured $d_{10}$ and $d_{60}$ can be assessed by the following relationship (e.g., International Organization of Standardization-GUM 1995)
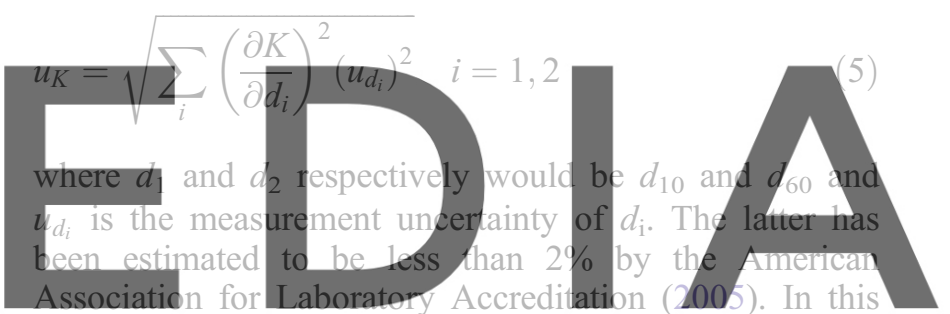

case, however, a conservative $2 \%$ value is used for the dostintis constant in Eqs. (2)-(4) (including gravity and physical properties of the fluid) are provided without uncertainty. On this basis, the uncertainty $u_{\mathrm{K}}$ was calculated to be less than $10 \%$ for $95 \%$ of the total number of samples. Uncertainty associated with IFM estimates of conductivity can then be derived on the basis of Eq. (1). This is however a delicate task, because, in addition to typical measurement uncertainties associated with pumping flow rates and length scales included in Eq. (1), one should also take into account the implications of the conceptual model adopted for the system. These analyses are seldom performed in the field with this degree of detail. For simplicity and for the sake of the demonstration example here, the matter is not pursued further in this work.

Table 3 Kolmogorov-Smirnov test parameters for the $\ln K_{F M}$ and $\ln K_{G S}$ data sets analyzed at the Tübingen site. All critical values are calculated for a significance level $\alpha=0.05$

\begin{tabular}{llll}
\hline Number of points & & K-S measure & Critical value \\
\hline $\ln K_{\mathrm{FM}}$ & $N_{\mathrm{IFM}}$ & 0.060 & 0.077 \\
$\ln K_{\mathrm{FM}}$ & $N_{\mathrm{MATCH}}$ & 0.074 & 0.129 \\
$\ln K_{\mathrm{GS}}$ & $N_{\mathrm{GSD}}$ & 0.096 & 0.067 \\
$\ln K_{\mathrm{GS}}$ & $N_{\mathrm{MATCH}}$ & 0.111 & 0.129 \\
\hline
\end{tabular}


Fig. 2 Normal probability plots for the $\ln K$ values obtained with a IFM and b GSD methods at the Tübingen site. Results obtained with the full data set and with data available at the $N_{M A T C H}$ locations are reported in gray and black, respectively
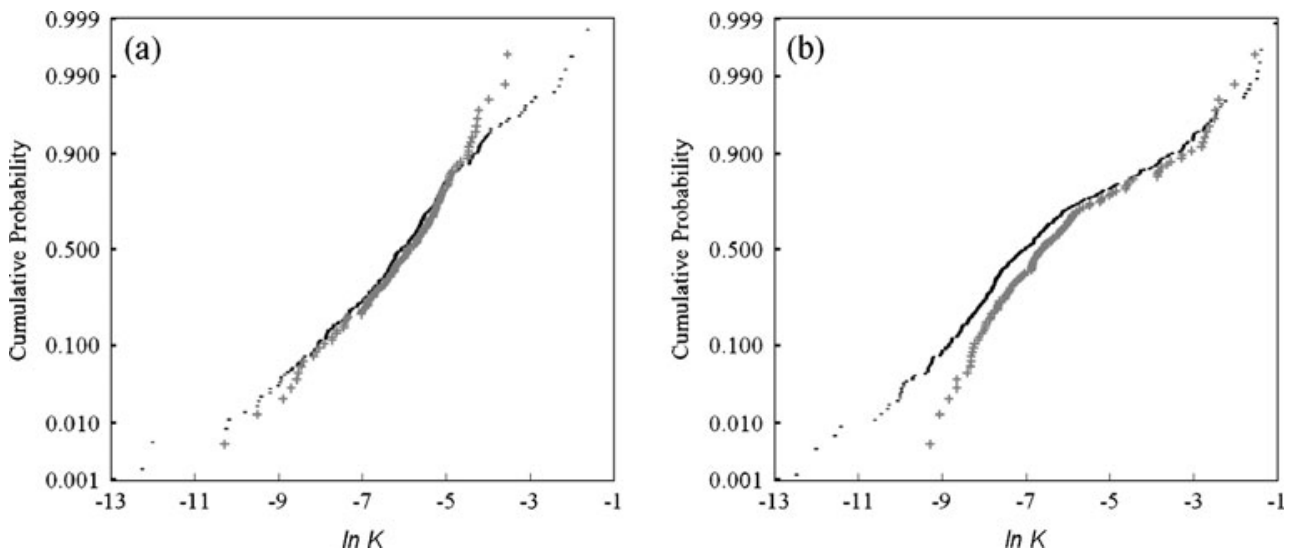

Additional details related to the uncertainty analysis performed are reported as ESM.

Sample histograms of the natural logarithm of all available hydraulic conductivity data, $Y=\ln K$ (conductivities are measured in $\mathrm{m} / \mathrm{s}$ ), estimated by means of IFM and GSD techniques are depicted in Fig. 1. A summary of basic univariate statistics is presented in Table 2 for the complete data-sets and for the subsets of conductivity values estimated only at the $N_{\mathrm{MATCH}}=112$ points where GSD and IFM data are jointly available. It is noted that

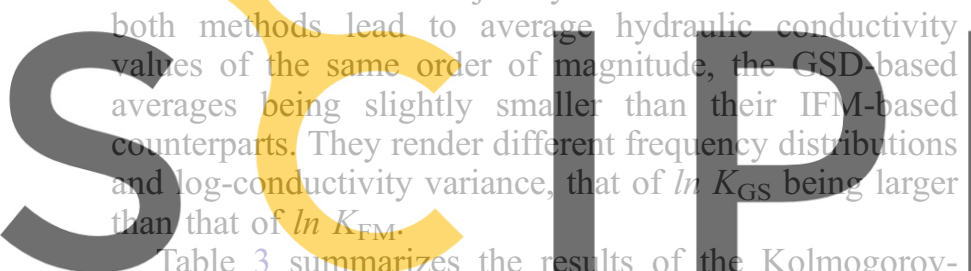

Smirnov (K-S) test performed at a significance level $\alpha=$ Regis 0.05 for the complete data-sets and for the subsets of data

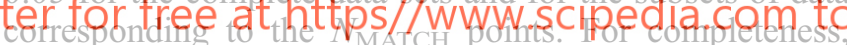

Fig. 2 reports normal probability plots for the four sample sets analyzed. The results evidence that the two sets of $\ln$ $K_{\mathrm{FM}}$ data pass the K-S test at $\alpha=0.05$, despite Fig. 2a evidence that the subset of $\ln K_{\mathrm{FM}}$ values corresponding to the $N_{\text {MATCH }}$ locations somehow undersamples the tail of the distribution corresponding to the largest conductivity values (this is also evidenced by the skewness values reported in Table 2). On the other hand, while the complete set of $\ln K_{\mathrm{GS}}$ data does not pass the K-S test of normality at $\alpha=0.05$, the subset representing the $N_{\text {MATCH }}$ locations does.
A t-test analysis was then performed to determine if the four data sets above mentioned can be considered as statistically different from each other. Table 4 summarizes the results of the tests performed upon analyzing different combinations of data set pairs at a significance level $\alpha=0.05$. These analyses indicate that the two data sets corresponding to all $K_{\mathrm{FM}}$ and $K_{\mathrm{GS}}$ available measurements are not representative of samples belonging to the same population at the chosen significance level. The observed differences suggest that, in general, GSD-based empirical formulations tand
to provide estinates of $Y$ which are characterizd by a
stronger spatial variability than those obtained by fFM
methods.
A geostatistical analysis yas then performed sepa-
rately for hydraulic conductivities obtained from each
method. Horizontal and vertical sample variograms were constructed. Two-point statistics for a given separation lag are considered only if these are calcudavendoad the versionstitiout tine Waternark

of theoretical models to interpret variograms is based on visual inspection of experimental data. Estimation of variogram parameters was performed on the basis of visual inspection.

Figure 3 shows the horizontal and vertical sample variograms of log-conductivities derived from IFM and GSD analyses of all available data together with the corresponding theoretical models adopted. Table 5 reports the main results of the three-dimensional geostatistical analysis. The results indicate that IFM and GSD techniques lead to different geostatistical depictions of the

Table 4 Calculated t values for the t-test analysis. Critical values are calculated for a significance level $\alpha=0.05$

\begin{tabular}{|c|c|c|c|c|c|}
\hline & & & Test statistic & Critical value & Result \\
\hline $\begin{array}{l}\ln K_{\mathrm{FM}}{ }^{\mathrm{b}} \\
\ln K_{\mathrm{FM}} \\
\ln K_{\mathrm{FM}} \\
\ln K_{\mathrm{GS}}\end{array}$ & $\begin{array}{l}\text { vs. } \\
\text { vs. } \\
\text { vs. } \\
\text { vs. }\end{array}$ & $\begin{array}{l}\ln K_{\mathrm{GS}}{ }^{\mathrm{b}} \\
\ln K_{\mathrm{GS}}{ }_{\mathrm{b}} \\
\ln K_{\mathrm{FM}} \\
\ln K_{\mathrm{GS}}\end{array}$ & $\begin{array}{l}0.627 \\
3.974 \\
0.667 \\
2.517\end{array}$ & $\begin{array}{l}1.96 \\
1.96 \\
1.96 \\
1.96\end{array}$ & $\begin{array}{l}\text { Not significant } \\
\text { Significant } \\
\text { Not significant } \\
\text { Significant }\end{array}$ \\
\hline
\end{tabular}

${ }^{\text {a }}$ All data points

${ }^{\mathrm{b}}$ Only matching points 
Fig. 3 a Vertical variogram for $\ln K_{F M}$, b vertical variogram for $\ln K_{G S}$, c horizontal variogram for $\ln K_{F M}$, and $\mathbf{d}$ horizontal variogram for $l n$ $K_{G S}$. Dashed line indicates the adopted variogram models
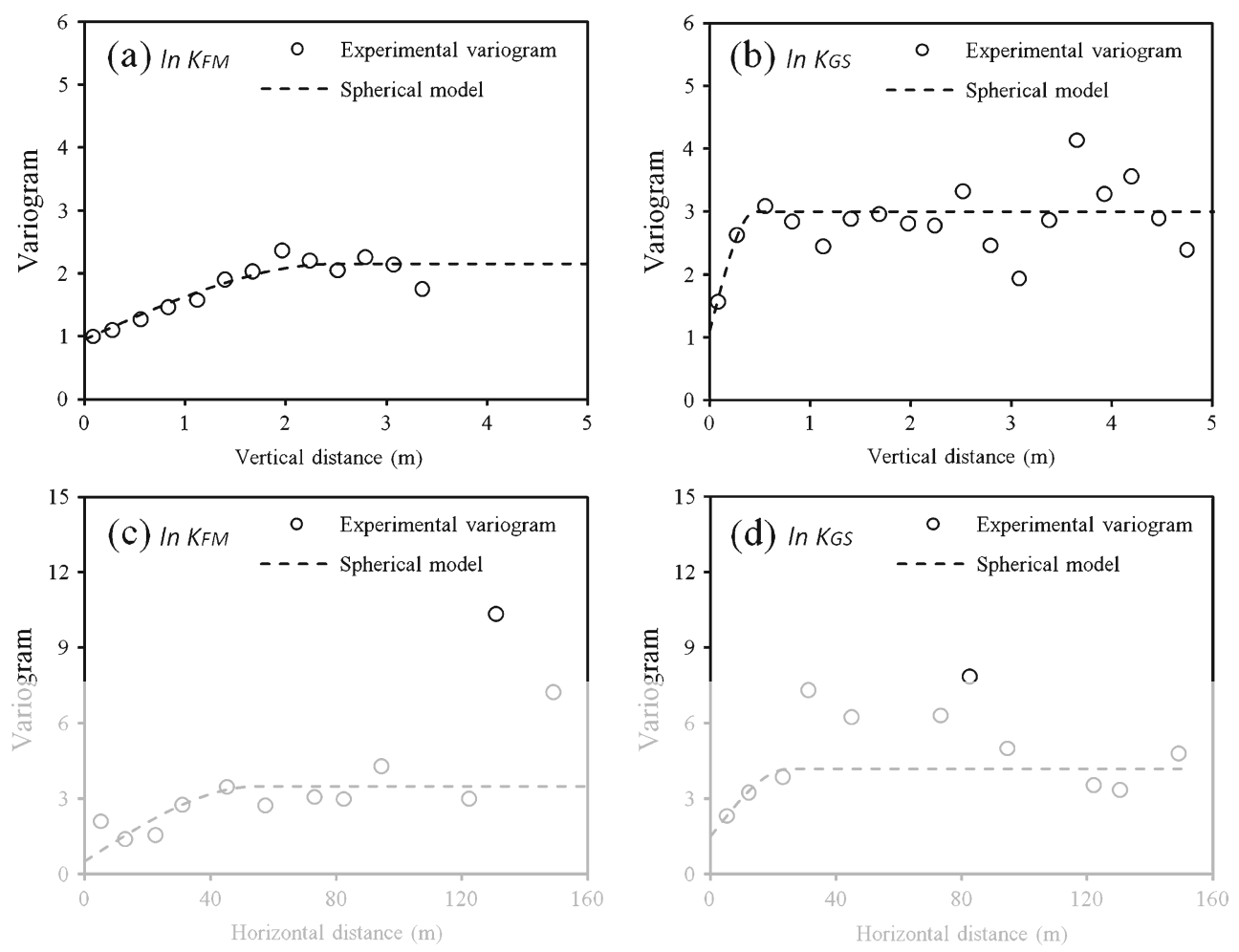
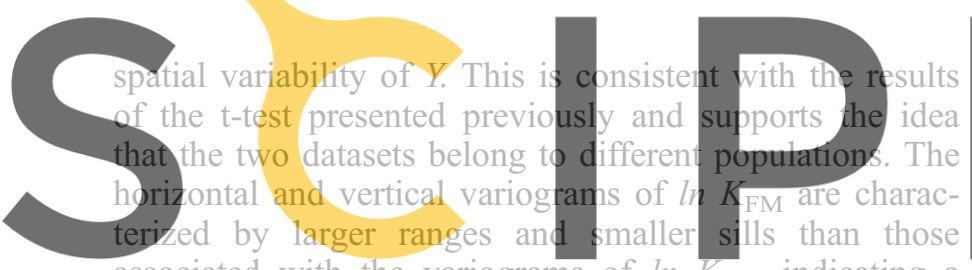
associated with the variograms of $\ln K_{\mathrm{GS}}$, indicating a stronger spatial persistence than that offered by $\ln K_{\mathrm{GS}}$. It

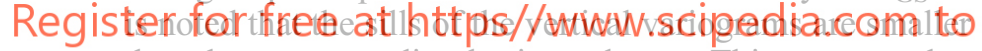
than the corresponding horizontal ones. This suggests that the total variance is mostly controlled by interwell (rather than intrawell) variability.

The reported findings are consistent with the fact that IFM- and GSD-based hydraulic conductivities can be interpreted as quantities associated with different, albeit of the same order of magnitude, support (measurement) scales. The former are somehow an average of the response of the system to a stress and reflect the local flow conditions around the well (including preferential paths, geological structures, effective porosity). The

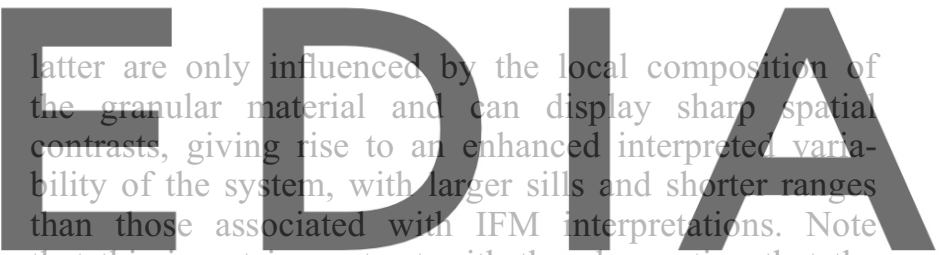

that this is not in contrast with the observation that the support scales of the two measurements are of the same

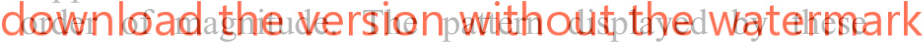
observations is in line with published results about variability of geostatistical parameters of conductivity on multiple support scales (e.g., Tidwell and Wilson 1999a, b; Neuman and Di Federico 2003).

\section{Correlation between data types}

The degree of correlation between $\ln K_{\mathrm{FM}}$ and $\ln K_{\mathrm{GS}}$ at the site is here explored, considering only $\ln K_{\mathrm{FM}}$ and $\ln$ $K_{\mathrm{GS}}$ data at the $N_{\mathrm{MATCH}}$ locations. The scatter plot presented in Fig. 4 shows the degree of correlation

Table 5 Results of the three-dimensional geostatistical analysis of $Y=\ln K$

\begin{tabular}{lllll}
\hline & $\ln K_{\mathrm{FM}}{ }^{\mathrm{a}}$ & $\ln K_{\mathrm{FM}}{ }^{\mathrm{b}}$ & $\ln K_{\mathrm{GS}}{ }^{\mathrm{a}}$ & \multicolumn{1}{c}{$\ln K_{\mathrm{GS}}{ }^{\mathrm{b}}$} \\
\hline Variogram type & Spherical & Spherical & Spherical & Spherical \\
Nugget & 0.95 & 0.50 & 1.10 & 1.50 \\
Range $(\mathrm{m})$ & 2.5 & 55 & 0.45 & 25 \\
Sill & 2.15 & 3.50 & 3.00 & 4.18 \\
\hline
\end{tabular}

\footnotetext{
a vertical direction

$\mathrm{b}$ horizontal direction
} 


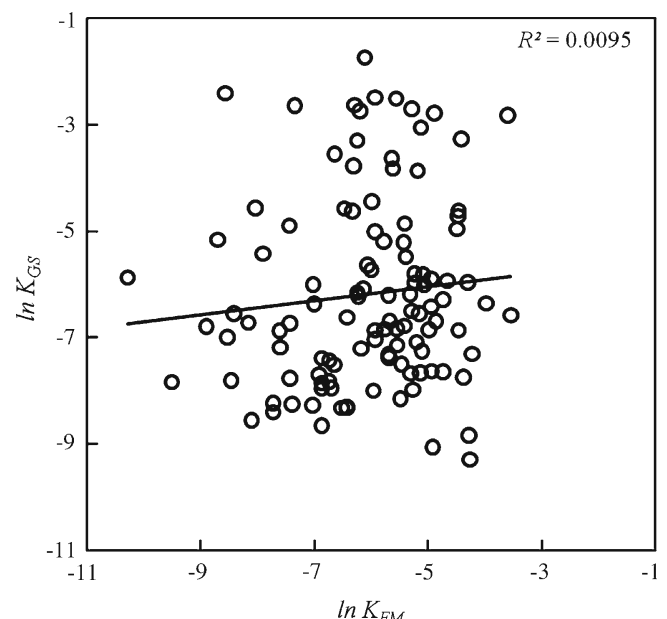

Fig. 4 Scatter plot of the $\ln K$ values obtained by the flowmeter method and grain sieve analysis. A weak correlation is noticeable in the graph. The value of the regression coefficient, $R^{2}$, is reported In $K_{\mathrm{GS}}$ values are weakly correlated with $\ln K_{\mathrm{FM}}$, the regression coefficient, $R^{2}$, being close to zero. The observed lack of correlation between the IFM and GSDbased measurements is also consistent with the spaceaveraging effect associated with downhole flowmeters, as

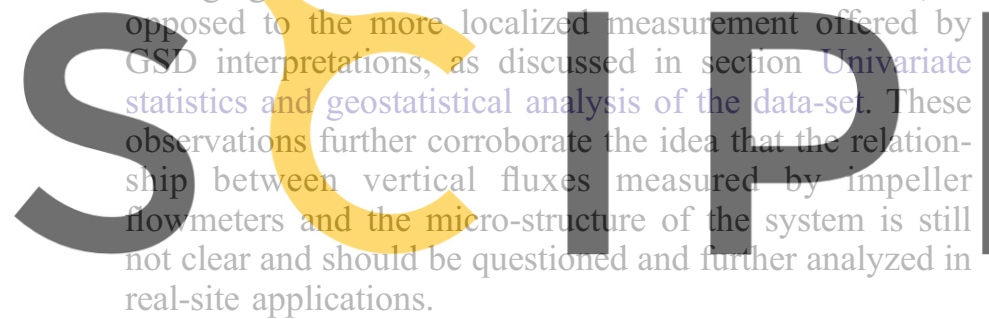

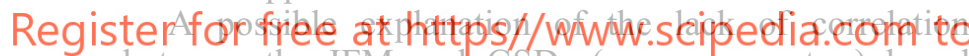
between the IFM and GSD- (or permeameter-) based measurements is that the former somehow average the response of the system to a stress and refiect the locai flow conditions around the well (including preferential paths, geological structures, effective porosity). This might also be consistent with the observation that IFM conductivity estimates are associated with the lowest variances and largest mean values and ranges. On the other hand, $K_{\mathrm{GS}}$ and $K_{\mathrm{P}}$ are only influenced by the local composition of the granular material. The latter can display sharp spatial contrasts, giving rise to an enhanced interpreted variability of the system, with larger sills and shorter ranges than those associated with IFM interpretations

\section{Conclusions}

A detailed analysis is presented of the basic statistics and key geostatistical parameters describing the three-dimen- sional spatial variability of hydraulic conductivities associated with measurement scales of the order of a few tens of $\mathrm{cm}$ within the alluvial aquifer located near the city of Tübingen, Germany. Hydraulic conductivities are obtained by means of impeller-type flowmeter measurements and particle-size sedimentological data at 112 coinciding locations in the system. The degree of correlation between conductivity values associated with interpretation methods based on impeller flowmeter measurements and particle-size distributions has then been explored. The work has lead to the following major conclusions.

1. The univariate statistical analysis of hydraulic conductivities estimated at the site highlights that the GSD-based average hydraulic conductivities are slightly smaller than their IFM-based counterparts. The analysis suggests that the variance of the natural logarithms of IFM estimates is smaller than that of GSD interpretations. From a statistical standpoint, the interpreted conductivities obtained with these methods appear to identify samples belonging to different populations.

2. At the site, the IFM-based log-conductivity variograms are generally characterized by larger ranges and smaller sills than those relying on GSD interpretations. As

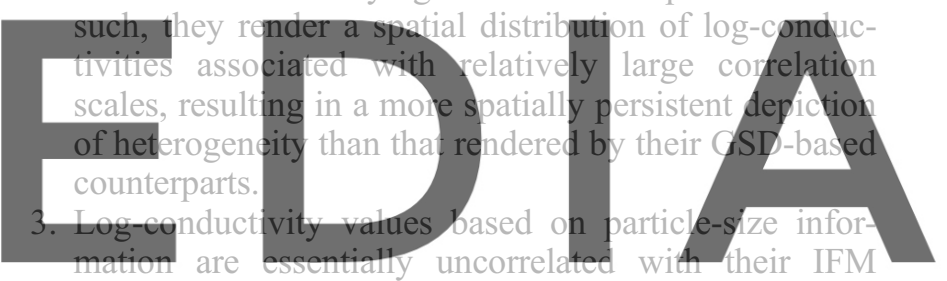
counterparts at the site, with linear regression coefdowiquadethe version without the watermark The three previous conclusions can all be associated with the fact that the IFM method provides estimates within a given borehole that somehow smooth or dampen actual (small-scale) natural variability, because the pressure distribution around the measuring device can be far from the theoretical distribution envisioned for homogeneous systems. On the other hand, GSDbased conductivities are only influenced by the local composition of the tested granular material. The latter can display significant spatial contrasts, resulting in larger sills and shorter ranges than those associated with IFM interpretations. These findings are consistent with the fact that the two types of estimates analyzed can be associated with different, albeit of similar order of magnitude, support (measurement) scales. Precise characterization of the support scale of any given information is thus needed to properly include hydraulic conductivity data into numerical models. This is particularly needed for the assessment of the support-scale-linked IFM conductivity measurement, which is still not completely clear. 
5. These results suggest that the relationship between vertical fluxes measured by impeller-type flowmeters and the micro-structure of the system is still not clear and should be tackled with great care in real site applications.

Acknowledgements Financial support from the Spanish Ministry of Science and Innovation through projects PARATODO and Consolider-Ingenio 2010 CSD2009-00065 is gratefully acknowledged. The first author was financed by the Consejo Superior de Investigaciones Científicas and the University of Costa Rica PhD scholarship. Additional funding was obtained from GEMINO (Politecnico di Milano, Progetti di ricerca 5 per mille junior). We are grateful to Thomas Ptak of the University of Göttingen in Germany for sharing with us data from the Tübingen site.

\section{References}

American Association for Laboratory Accreditation (2005) P103dAnnex: policy on estimating measurement uncertainty for construction materials \& geotechnical testing labs. AALA, Frederick, MD

Barr DW (2005) Discussion of "Goodbye Hazen; hello, KozenyCarman" by W. David Carrier III. J Geotech Geoenviron Eng 131(8):1057-1058

Beckie R (1996) Measurement scale, network sampling scale, and

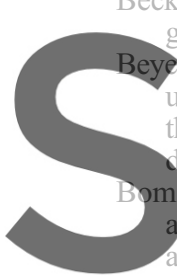
groundwater model parameters W (1964) Zur Bestimmoung der. Wr Wanden aus der Kornverteilu the hydraulic conductivity of grave

Boman GK, Molz FJ, Boone K sessment Ground Water $35(3): 443-450$

Butler JJ (2005) Hydrological methods for estimation of spatial variations in hydraulic conductivity. In: Rubin Y, Hubbard S

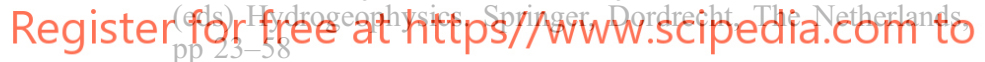

Cardenas MBR, Zlotnik VA (2003) Constant-head injection tests: a simple method for streambed permeability estimation. Ground Water 41(6):867-871

Carrier WD (2003) Goodbye, Hazen; hello, Kozeny-Carman. J Geotech Geoenviron Eng 129(11): 1054-1056

Cheng C, Chen X (2007) Evaluation of methods for determination of hydraulic properties in an aquifer-aquitard system hydrologically connected to a river. Hydrogeol J 15:669-678

Custodio E, Llamas MR (1984) Hidrología subterránea [Subterranean hydrogeology]. Barcelona, Spain

Fetter CW (2001) Applied hydrogeology. Englewood Cliffs, NJ

Fogg GE, Noyes CD, Carle SF (1998) Geologically based model of heterogeneous hydraulic conductivity in an alluvial setting. Hydrogeol J 6:131-143

Gallardo AH, Marui A (2007) Hydraulic characteristics of sedimentary deposits at the J-PARC proton-accelerator, Japan. Earth Sci Res J 11(2):139-154

Hess KM, Wolf SH, Celia MA (1992) Large-scale natural gradient tracer test in sand and gravel, Cape Cod, Massachusetts, 3: hydraulic conductivity variability and calculated macrodispersivities. Water Resour Res 28(8):2011-2027

Hufschmied P (1986) Estimation of three-dimensional statistically anisotropic hydraulic conductivity field by means of a single well pumping test combined with flowmeter measurements. Hydrogeologie 2:163-174
International Organization of Standardization-GUM (1995) Guide to the expression of uncertainty in measurements. JCGM, Pavillon de Breteuil, France, pp 1-15

Kasenow M (2002) Determination of hydraulic conductivity from grain size analysis. Water Resources, LLC, Highlands Ranch, $\mathrm{CO}, \mathrm{pp}$ 47-84

Martac E, Ptak T (2003) Data sets for transport model calibration/ validation, parameter upscaling studies and testing of stochastic transport models/theory. Report D16 of Project "Stochastic Analysis of Well-Head Protection and Risk Assessment-WSAHaRA", EU contract EVK1-CT-1999-00041, Dipartimento Ingegneria Idraulica, Ambientale, Infrastrutture Viarie, Rilevamento, Politecnico di Milano, Milan, Italy

Molz FJ, Morin RH, Hess AE, Melville JG, Güven O (1989) The impeller meter for measuring aquifer permeability variations: evaluation and comparison with other tests. Water Resour Res 25(7):1677-1683

Molz FJ, Bowman GK, Young SC, Waldrop WR (1994) Borehole flowmeters: field application and data analysis. J Hydrol 163(34):347-371

Neuman SP, Di Federico V (2003) Multifaceted nature of hydrologic scaling and its interpretation. Rev Geophys 41(3):1014. doi:10.1029/2003RG000130

Neuman SP, Blattstein A, Riva M, Tartakovsky DM, Guadagnini A, Ptak T (2007) Type curve interpretation of late-time pumping test data in randomly heterogeneous aquifers. Water Resour Res 43(10):W10421

Neuman SP, Riva M, Guadagnini A (2008) On the geostatistical characterization of hierarchical media. Water Resour Res 44(2): W02403

Odong J (2007) Evaluation of empirical formulae for determination of hydraulic conductivity based on grain-size analysis. J Am Sci

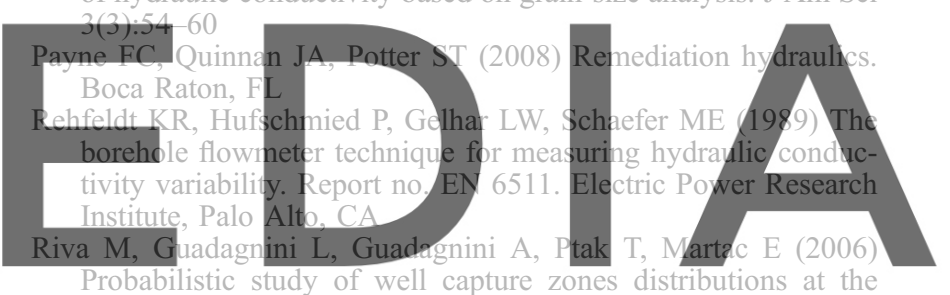
Lauswiesen field site. J Contam Hydrol 88:92-118

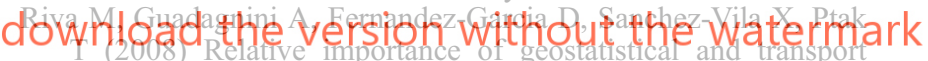
models in describing heavily tailed breakthrough curves at the Lauswiesen site. J Contam Hydrol 101:1-13

Riva M, Guadagnini L, Guadagnini A (2010) Effects of uncertainty of lithofacies, conductivity and porosity distributions on stochastic interpretations of a field scale tracer test. Stoch Environ Res Risk Assess 24:955-970

Sack-Kühner BT (1996) Einrichtung des Naturmeßfeldes "Lauswiesen Tübingen", Erkundung der hydraulischen Eigenschaften, Charakterisierung der Untergrundheterogenität und Vergleich der Ergebnisse unterschiedlicher Erkundungsverfahren [Installation of the natural measuring field "Lauswiesen Tübingen", investigation of the hydraulic characteristics, characterization of the underground heterogeneity and comparison of the results for different investigation procedures]. MSc Thesis, University of Tübingen, Germany

Sanchez-Vila X, Guadagnini A, Carrera J (2006) Representative hydraulic conductivities in saturated groundwater flow. Rev Geophys 44(3):RG3002

Stauffer TB, Manoranjan VS (1994) The use of grain-size analysis field-data to study hydraulic conductivity variability. Aviat Space Environ Med 65(5):A125-A130

Tidwell VC, Wilson JL (1999a) Permeability upscaling measured on a block of Berea sandstone: results and interpretation. Math Geol 31(7):749-769 
Tidwell VC, Wilson JL (1999b) Upscaling experiments conducted on a block of volcanic tuff: results for a bimodal permeability distribution. Water Resour Res 35(11):3375-3387

Vukovic M, Soro A (1992) Determination of hydraulic conductivity of porous media from grain-size composition. Water Resources, Littleton, CO

Whittaker J, Teutsch G (1999) Numerical simulations of subsurface characterization methods: application to a natural aquifer analogue. Adv Water Resour 22(8):819-829

Wilson AM, Huettel M, Klein S (2008) Grain size and depositional environment as predictors of permeability in coastal marine sands. Estuar Coast Shelf Sci 80(1):193-199

Wolf SH, Celia MA, Hess KM (1991) Evaluation of hydraulic conductivities calculated from multiport-permeameter measurements. Ground Water 29(4):516-525

Young SC (1998) Impacts of positive skin effects on borehole flowmeter tests in a heterogeneous granular aquifer. Ground Water 36(1):67-75
Zlotnik VA, McGuire VL (1998) Multi-level slug tests in highly permeable formations: 2 . hydraulic conductivity identification, method verification, and field applications. J Hydrol 204:283296

Zlotnik VA, Zurbuchen RF, Ptak T, Teutsch G (2000) Support volume and scale effect in hydraulic conductivity: experimental aspects In: Zhang D, Winter CL (eds) Theory, modeling, and field investigation in hydrogeology: a special volume in honor of Shlomo P. Neuman's 60th Birthday: Boulder, Colorado," Geological Society of America Special Paper 348, GSA, Boulder, CO, pp 215-231

Zlotnik VA, Zurbuchen BR (2003a) Field study of hydraulic conductivity in a heterogeneous aquifer: Comparison of single-borehole measurements using different instruments. Water Resour Res 39(4). doi:10.1029/2002WR001415

Zlotnik VA, Zurbuchen BR (2003b) Estimation of hydraulic conductivity from borehole flowmeter tests considering head losses. J Hydrol 281:115-128
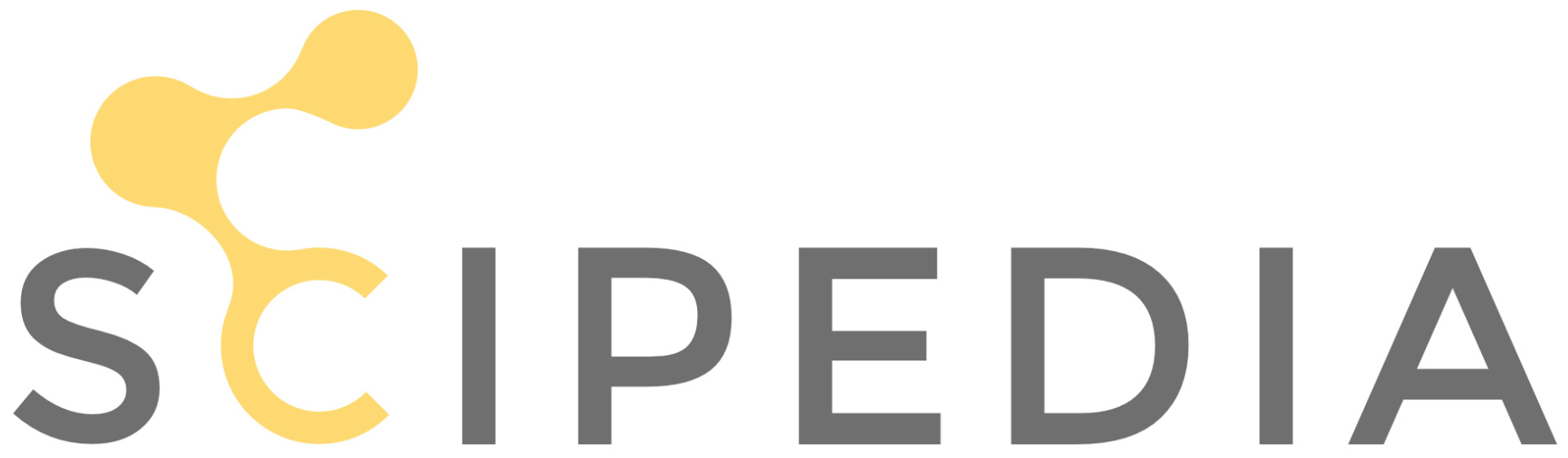

Register for free at https//www.scipedia.com to download the version without the watermark 